\title{
5. Whose census? Institutional constraints on the Indigenous Enumeration Strategy at Wadeye
}

\section{John Taylor}

The 2006 Census enumeration in the Thamarrurr region provides an example of the logistical and cross-cultural issues associated with implementation of the Indigenous Enumeration Strategy (IES) in a large Aboriginal town (Wadeye) and surrounding outstations (Figure 5.1). In the past 30 years, many former mission and government settlements across northern Australia that were established for the purposes of administering Aboriginal welfare polices have grown steadily in size and complexity, with several now achieving the status of 'urban centre' (more than 1000 people) within the Australian Standard Geographical Classification (ASGC). Among those with populations that now exceed this number are: Wadeye, Maningrida, Nguiu, Galiwinku, Milingimbi and Ngukurr (in the Northern Territory) and Aurukun, Palm Island, Yarrabah, Doomadgee, Mornington Island, Woorabinda and Cherbourg (in Queensland). The population trajectory for these towns is for continued growth while many more such 'urban' places are expected to emerge in time. Consequently, the observations made in respect of census operations at Wadeye are representative of a category of Aboriginal settlement that will be of increasing relevance for the IES and to Indigenous affairs policy in the future.

There are other ways in which Wadeye is representative of an emergent type. As a polyglot, overcrowded, under-resourced and growing settlement that has drawn disparate social groups from surrounding country (Taylor and Stanley 2005), Wadeye presents a set of social, economic and governance difficulties that are increasingly evident across remote Australia (Ah Kit 2002; Dillon 2007; Westbury and Dillon 2006) and that provide an essential backdrop to any assessment of the conduct of census operations and their effectiveness. Among these, at Wadeye, is a scale of anomie, especially among youth, that has led at times to outbreaks of civil disorder. For example, in April and May 2006, just two months before the planned census date, many of the town's residents - anecdotal estimates of up to 500 were cited locally - had fled to set up temporary residence across the immediate region and beyond because of relentless inter-family feuding and destruction of property (a similar situation had occurred at the time of the previous census in 2001). Part of the fallout was a delay in conducting a ballot for the Thamarrurr Regional Council (TRC), with the elected body in abeyance for a period until new elections could be arranged in mid July. This not only complicated communication with community 
representatives regarding census preparations, it also meant that the council and the people were preoccupied with electoral matters in the crucial weeks leading up to census day.

\section{Fig. 5.1 Settlement geography of the Thamarrurr region}

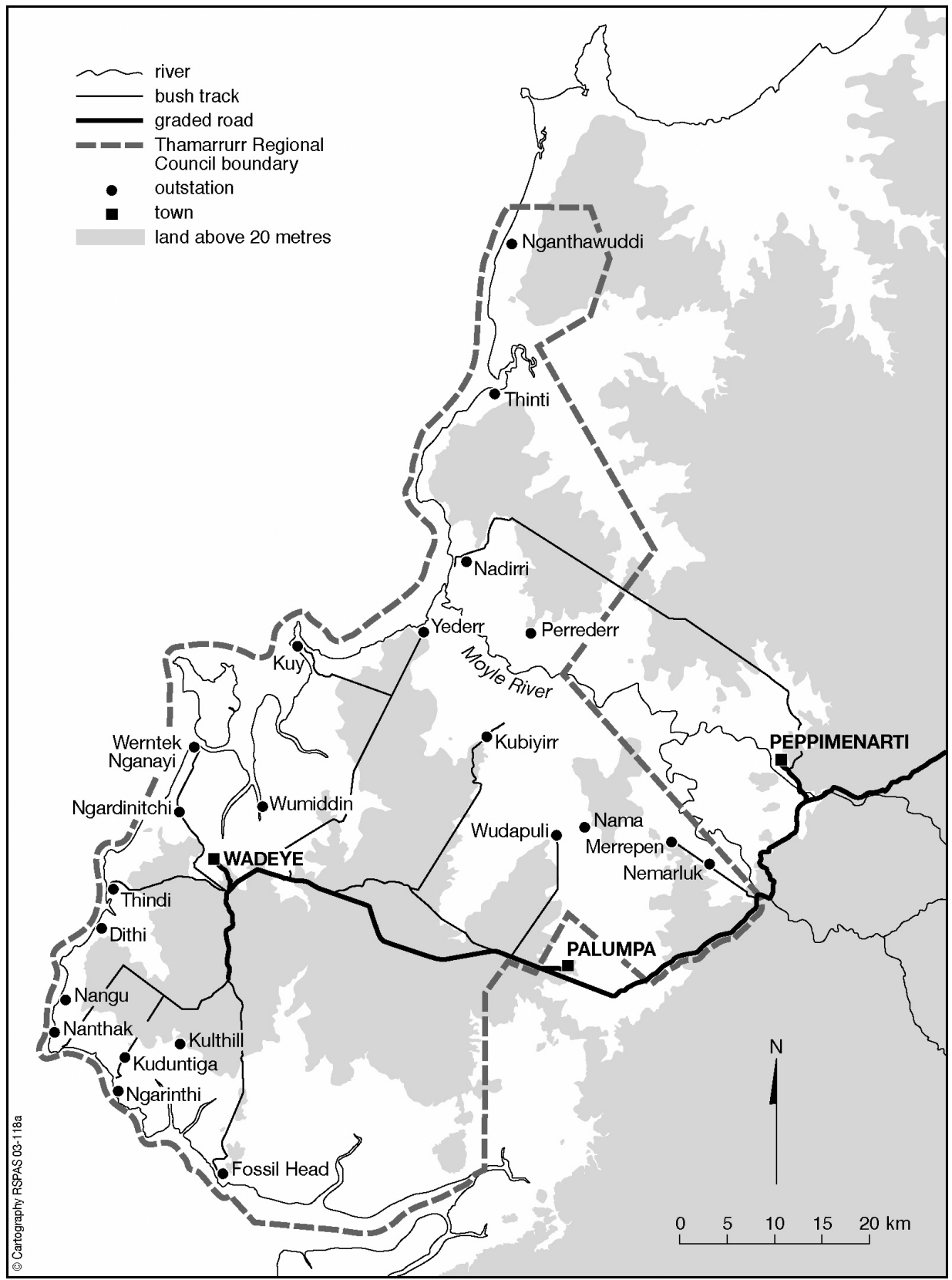


Needless to say, these were not ideal conditions in which to plan and conduct a census enumeration, and they underline the fact that the IES does not operate on a blank canvas. In order to be successful as a strategy, it is - or at least it should be - as much about having the capacity to anticipate and successfully negotiate these sorts of contingencies as anything else. One of the key questions posed by the research team was whether the strategy adopted for the enumeration of remote Indigenous communities was suitably adapted to meet the cultural and contingent situations encountered. By force of circumstances such as those above, the focus of census observation at Wadeye was concerned substantially with this question.

Along the way, two weeks spent at Wadeye and its outstations observing the census training and most of the census enumeration between 24 July and 6 August, together with subsequent follow-up, also provided a unique opportunity to witness at close hand the process of translation between two cultures: the local Indigenous community and the nation-state. This was manifest in several arenas: in the handling of interactions with community leadership, in the strategies adopted to engage, train and supervise an Indigenous census workforce, in the logistics deployed to connect with a mobile and scattered population and in the categorisations and interpretations associated with the questions on the census questionnaire. Other, more specific, issues concerning innovations in the structure of the Interviewer Household Form (IHF) were considered secondary to these more generic concerns, not because they were less important, but because they turned out to be of less consequence. They are discussed in Appendix B.

\section{Census preparation: the relationship between the community and the Australian Bureau of Statistics}

As noted, the IES does not unfold in a vacuum. In each Indigenous settlement there will be particular cultural and governance dynamics that can substantially influence the conduct of field operations. This is because - in stark contrast with the mainstream census - the interview format of the IES in remote settlements creates an encounter not just with individuals and their households, but with a social collective and related representative and administrative structures. This creates an institutional arrangement whereby councils and other local organisations can act as the interface between populations to be counted and the state (instantiated in this case by the Australian Bureau of Statistics [ABS] and its census).

In terms of the collective, the population of the Thamarrurr region is embedded in dense social networks across some 40 extended paternal family groups with affiliations to 20 locally defined and recognised clans. While members of all of these social units are present in the town of Wadeye, country and family ties beyond the town produce a population that is widely and variously scattered at any one time at local outstations and in neighbouring communities and towns 
across an area from as far south as Kununurra and Timber Creek through the Daly region and north to the Cox Peninsula and Darwin. This is especially so in the dry season around census time and within this network there is considerable short-term mobility. This configuration immediately raises a set of questions regarding what properly constitutes the population of the Thamarrurr region and how best this might be counted. In 2006, the ABS adopted a de facto enumeration to address this question - that is, assigning people to the place where they were found at census time rather than to the place where they usually lived - but issues still arose regarding the impact of frequent mobility and the consequent adequacy of de facto and usual resident counts. These are dealt with later.

As for representative and administrative structures, a significant development at Wadeye was the formation in 2003 of the TRC as a local government body built around representation from the 20 clans. At the same time, the TRC entered into a Shared Responsibility Agreement (SRA) with the Commonwealth and Northern Territory governments as one of several Council of Australian Governments (COAG) trial sites for Indigenous Communities Coordination Pilot projects aimed at effecting whole-of-government cooperative approaches to service delivery. These were based on the idea of streamlining government processes and supporting some restoration to local Indigenous populations of responsibility for, and control over, decision-making regarding service delivery and general planning for social and economic development. Within this arrangement, the TRC gained a substantial local profile and presence and it is fair to say that the council assumed its new responsibilities with some vigour. One activity it conducted under the auspices of the COAG trial was its own census of usual residents in 2003, and again in 2005. These activities were undertaken for the explicit reason that previous census counts conducted by the ABS were felt by the TRC to have been deficient given their own estimation of numbers in the region. A number of salient points flow from all of this.

In the period leading up to the census, the TRC had established itself as a prominent institution heavily involved with government in a partnership approach to regional social planning with strong interests in census-taking. As part of these and related survey activities - including by the ABS, for example, in the 2002 National Aboriginal and Torres Strait Islander Survey - a small cadre of experienced local enumerators had been developed and the council was keen to nurture this expertise. By 2006, however, after almost three years of participation in the COAG trial, the experiment in whole-of-government approaches to service delivery had all but collapsed, with very few beneficial outcomes and a loss of confidence at Wadeye in the COAG process (Commonwealth of Australia 2006: 27-33). It was into this environment of initial local optimism and then despair at the state's intentions that the ABS Census Management Unit (CMU) based in Darwin was about to step. 
That is not to say that community-government relations were never propitious. In line with its pursuit of regional planning and cognisant of the approaching 2006 Census, the TRC and the ABS began in late 2005 to explore ways to ensure that people in the region were well prepared to participate optimally in the enumeration. Discussions with census officials were held at Wadeye and in Darwin, and an attempt was made to arrange for a workshop at Wadeye to explain the census questions and for this to be communicated in Murrinh-patha in line with council practice. The fact that this workshop failed to eventuate meant that by the time the enumeration finally began in late July, the council - and through it, the community - felt little ownership of or familiarity with the census content and process. By then, some council members expressed the view that the ABS alone had carriage and responsibility for the census. This was a far cry from the partnership approach to regional planning that had prevailed earlier and it meant that, for the most part, the census was going to be an encounter directly between the ABS and individual householders - a far more difficult task than working in effective collaboration with the council (see Sanders, Chapter 3 for the benefits of working in partnership with representative structures).

Consequently, communications regarding final census logistics between the ABS and the interface with the population to be counted became somewhat perfunctory. Almost inevitably, given the Census Field Officer's (CFO) myriad responsibilities in preparing for the census across a vast area from Lajamanu to the Tiwi Islands, these communications were compressed in time and content. For example, before and during the conduct of the Community Housing and Infrastructure Needs Survey (CHINS) at Wadeye (at the end of April), a request was made to the TRC for assistance in mustering a census workforce of 20-30 local people. The limited opportunity for effective follow-up (just one visit in early July) meant, however, that by the time census training began in late July the task of mustering an interview team was still to be done. At an earlier visit, an approach was made to the Thamarrurr Regional School to obtain assistance with census workers, but to no avail, given staff commitments. As for advertising the census, the usual publicity packs were distributed via the council and the school, while a brief explanation of the purpose of the census was broadcast by a member of the TRC on Broadcasting for Remote Aboriginal Communities Scheme (BRACS) radio. Other attempts to pursue logistics were made by the CFO via phone and email in the lead up to census day, either from Darwin or on the road in other communities. Not surprisingly, such communication from a distance proved ineffective in terms of preparing a census workforce. According to the CFO, the TRC administration was keen to assist, but any prospective workers were already fully occupied in their normal jobs. In the meantime, the TRC provided a map of all dwellings in Wadeye and at outstations, but it was reluctant 
to supply a copy of the Thamarrurr population database, as requested, as it regarded this as confidential.

In practical terms, what eventuated from all of these interactions, on the very eve of planned commencement of the census, was the deployment of two TRC staff- one local Aboriginal person as a collector-interviewer (CI) and one recently arrived non-Aboriginal person as a Community Coordinator (CC)-a council vehicle for travel around town and to outstations and council assistance on the first day of interviewer and CC training in driving around the community to mobilise potential interviewers. The TRC also provided exclusive access to a training room, and later an office, to serve as a base for the duration of census operations, which turned out to be more than a calendar month.

Interestingly, at the same time that these arrangements had been established, another Commonwealth agency, Centrelink, had also assembled teams of six Commonwealth officers to conduct a survey in Wadeye and across the region asking householders many of the same questions as the ABS regarding resident population, family composition, income and employment. While no observation of the possible impact of this on the conduct of the census was possible, to the extent that any repetition involved might have confused or irritated residents, at the very least it suggests a lack of coordination between Commonwealth agencies.

By the time the census enumeration began in Wadeye on 26 July, the impression obtained from discussion with key informants was of a regional population that was largely ignorant of the imminent census activities, that was administratively detached from the process and that was otherwise diverted by issues of more pressing concern including elections and Centrelink processing. One important practical consequence, as we shall see, was a failure to engage the small cadre of experienced interviewers who had been used for a variety of previous local surveys and potential local CCs who had some standing in the community and knowledge of the population, because by census time they were all fully engaged in other work. It also meant that the time available for CC and CI training was highly restricted.

\section{Census preparation: engaging a local census team}

As noted, in the lead-up to the census at Wadeye, the CFO had assessed that an interview team of 20-30 people would be required for the task, assisted by four CCs. This estimate was based on a calculation involving the idea that the CFO and Assistant CFO would be back in Darwin by 8 August for the start of the mainstream census, and that the Wadeye enumeration would be completed fully by then - a proposed enumeration time of eight working days. Against this schedule, given the estimated number of people to be counted and the estimated 
time required to administer the 55-question IHF, this workforce target was not unreasonable. It was, however, unrealistic under the circumstances.

On the morning of 24 July, the CFO arrived in Wadeye and the TRC Housing Office training room was made available to begin the census process. The first activity scheduled was for the CFO and his Assistant to explain the nature of the task to potential census interviewers, then to provide a day of training on how to administer the census form. Simultaneously, the newly recruited CCs - the seconded TRC employee and a non-Indigenous male who had been resident at Wadeye for a year and employed variously as a casual worker-were to be instructed in their roles. As the CFO's plan was to be in Palumpa, Peppimenarti and Daly River by 27 July to begin the same procedures there, three days were set aside in order to assemble this workforce, sign them up as ABS casual labour, train them and satisfactorily deploy them to be left in the capable hands of the CCs. This turned out to be an ambitious timetable and one that was dictated more by the pressures on the CFO to administer such a vast census area than by any proper consideration of real training needs.

Almost inevitably, it was nearly midday on day one before a group of interested people finally assembled in the training room. By the time lunch was provided, there were 13 potential CIs present (nine women and four men), but by the time lunch was over only seven people (five women and two men) remained for the training. This manoeuvring continued throughout the next day, leading to substantial turnover during training, involving 22 individuals out of whom only six (four women and two men) finally signed up as census interviewers, although in effect only four participated in enumeration since one of these served as an interpreter for one of the CCs and one withdrew early on. One consequence of this substantial shortfall in labour was that the CCs spent most of their time operating as census interviewers and less time on coordinating and assisting the activities of interviewers. This was unfortunate as the interviewers were deployed singly, and not in pairs, while CC support was physically limited. As a result, any errors or omissions on IHFs had to be discussed and dealt with back at the training room at the end of each day rather than addressed in situ.

\section{Training}

Training in the application of the IHF began after lunch on the first day. Taking into account technical glitches and a short break, it lasted for just one and a half hours. It was constructed around a viewing of the census DVD - which was delayed owing to technical difficulties and the fact that many of those present before lunch failed to return - with breaks for discussion. Views on the content and effectiveness of this training were sought from participants afterwards and the following is a precis. The DVD presentation was set in the New South Wales South Coast community of Wreck Bay. One view offered by the local participants was that this setting was too mainstream for the Wadeye context, with interviews 
conducted indoors in unfamiliar settings (well-furnished lounge and kitchen areas) among small social units. Most participants would also have preferred the presentation and discussion of census content and process to have been conducted in Murrinh-patha rather than English. Although the CFO halted the presentation occasionally to solicit any questions, all this produced was a blanket silence as opposed to the robust discussion in language that one often hears at Wadeye. People had questions, they just didn't ask them.

As noted, the basic instruction method was to halt the DVD periodically and attempt a discussion of the issues presented. In effect, what this provided was an opportunity for the $\mathrm{CFO}$ to establish certain standards in answering particular census questions. For example, it was suggested by one participant that $\$ 40$ a dwelling should be indicated on the IHF in answer to Question 5 about rent. The Assistant CFO checked this subsequently with the TRC and the idea that each adult paid $\$ 10$ a week was tabled. The general outcome observed during enumeration was some confusion about the real amounts inserted. This was partly because of the location of the rent question on the census form (at Question $5)$, which preceded the lengthy business of establishing the real occupants of dwellings including adults (Question 12), from which a retrospective calculation of rent could be derived. Similar conformity was sought for Question 13 on family relationships, though how this was to be achieved remained unresolved. The main advice was that CIs should think in terms of 'whitefella' categories, not local ones, and that if individuals were not clear they should defer to the CCs. The problem here was that the CCs had no idea how to translate local family relationships into 'whitefella' categories. Instances of such efforts observed during enumeration revealed that individual interviewers worked through the nuances themselves, so any notion that a common understanding prevailed can be discounted.

For Question 12, one of the CCs suggested using TRC administrative data on dates of birth (DOB) in the event that people did not know these - which turned out to be very common. This suggestion was, however, overruled by the CFO as too complex an arrangement, with a preference expressed for acquiring DOB information from the interview. On income (Question 40), the CFO offered to find out standard rates regarding how much people received from various allowances and pensions as well as from the Community Development Employment Projects (CDEP) each fortnight. Although this was never established, the amounts tended to be standardised anyway, with CIs acting intuitively in the field, aided by the grouped nature of income categories on the census form. For Question 46 about the person's employer, the instruction was to classify any activities associated with the TRC as 'community services' even though these could include a diverse range of industry types. Strangely, the DVD content then jumped from Question 25 to 40, so no discussion of the intervening questions 
was held. Along the way, an ad hoc list of common spellings was compiled for use in the field, although this was rarely utilised in practice.

At the end of the first day, the prevailing view of the training session among local participants was that far too much information was provided in too short a time, with the added difficulty that none of this was in Murrinh-patha. This referred not just to the census content, but to the many administrative details related to interviewer pay and conditions. While in practical terms the effect was high attrition during training, a fair degree of confusion was also evident among those who remained. This all left the CFO and his Assistant somewhat anxious given the time pressure on them to instigate the process and move on to the next community. They were hopeful, however, that a more hands-on approach on day two, with individuals practising by interviewing each other, would help to progress matters. This did, in fact, turn out to be more effective in generating understanding among the six interviewers who persisted through day two. As a precaution, however, the CFO had organised a team of ABS officers to stand by in Darwin to assist with the census if necessary, and arrangements had been made with the TRC to reserve accommodation for them.

\section{A small workforce and its consequences}

One important consequence of ending up with a much smaller workforce than hoped for was a lack of representation from across the local socio-cultural spectrum. Of the four effective interviewers and the translator, all were Murrinh-patha speakers but only one had affiliation with the large Marri Ngarr language group, and none with the other large language group, Marritjevin. Together, affiliation with the latter two language groups encompasses about two-thirds of the population of the Thamarrurr region. While the use of Murrinh-patha as a lingua franca in the region reduced the impact of this shortcoming at the level of communication, the fact that language and clan affiliation often graft on to social groupings and residential location meant that interviewing in certain parts of Wadeye became problematic, if not impossible, for most of the team - especially in light of recent communal animosities. While it is not clear how this affected the population count, it was apparent that interviewers were focused mostly on their 'own' areas of town, leaving certain other areas - and therefore particular social groupings - to be covered largely by the non-Indigenous CCs.

Of course, the ultimate consequence of a small workforce was that the count took much longer than was planned for. In fact, rather than taking the eight working days originally hoped for, the enumeration was pursued over 33 working days - from 26 July to 9 September, excluding weekends and two public holidays. Not surprisingly, perhaps, during this extended period the local enumeration team experienced gradual attrition with the final stages of 
enumeration conducted by just one of the CCs, and ultimately by the CFO and his Assistant. There were a number of reasons for this outcome.

First, the limited training provided for what was an inexperienced team meant that systems were learnt mostly on the job by working through the interview schedule - with mixed results. An important rider here is that none of the interviewers, when questioned, indicated that they had read the Interviewer Household Form Guide or the Working for the Census booklet that were provided with the census bag. The outcome was that while some of the CIs struggled throughout with form completion and administration, others learnt quickly, although all found the task arduous. Part of the issue here was the sheer length of the form with its 55 questions and the need to extract data for every household member. This meant that interviewing was often lengthy, with one dwelling observed taking a whole morning to interview. It should be emphasised, however, that the new, compact, single-form structure of the IHF compared with the two forms previously used did prove highly practical to administer - even in simple ways such as when questioning people under trees or on verandahs in the often blustery conditions of the Top End dry season.

Second, at the end of each day, the process of checking and reconciling the many data items from the front of the IHF with the Interviewer Dwelling Checklist (IDC) and the Master Dwelling Checklist (MDC) was at times chaotic as essential details had not always been completed in the field and forms were sometimes mixed up on return to the Housing Office training room. Third, as they proceeded through the census, most interviewers became enmeshed in social demands from their own family members - such as child minding, card games, shopping, providing meals, visits to the clinic and so on - and the combined effect was a variable rate of progress. The fact that lunch was not provided to interviewers also meant that they tended to stray in the middle of the day and it was difficult for the CCs to gain a regular sense of overall progress.

Finally, conscious of the fact that they were being paid piecemeal rates $-\$ 3.29$ for each person enumerated - some of the CIs could see that their commitment to the process, over what was turning out to be a longer and more arduous period than expected, was providing diminishing returns to effort, not least because of delays in receiving payment from Darwin, and enthusiasm waned accordingly. On this last point, issues regarding payment for services were something of a running sore from day one. Some of the interviewers had been removed from their standard payroll in order to participate in the census and while ideas were floated early on about the TRC possibly paying them and then invoicing the ABS, the fact is some individuals experienced considerable delay in being recompensed. This led to the unusual situation in which one of the CCs was paying amounts personally out of pocket to be reimbursed later on a visit to the CMU in Darwin. 


\section{Counting a mobile population}

As mentioned, the population usually resident in the Thamarrurr region is distributed at any one time across a wide area from the east Kimberley and Victoria River valley through to Darwin, though with most found within the region at Wadeye and surrounding outstations. The settlement geography of the Thamarrurr region is shown in Figure 5.1. Most people live in the town of Wadeye but there are some 20 other localities - all outstations - where families also reside, either permanently or occasionally. Most of these have some housing and basic infrastructure, while some have none. As the map indicates, these outstations are located either at coastal sites or on slightly elevated ground above floodplains. Aside from the relative lack of housing and basic services, a major factor that restricts more full-time use of these sites is the poor condition of regional roads and bush tracks, although in August at census time all localities are accessible. Indeed, this is the time of maximum population dispersal across the Top End because of the relative ease of travel. The people of the neighbouring communities of Palumpa and Peppimenarti also have strong social ties with people at Wadeye, and the overwhelming feature of interaction between all of the settlements shown in Figure 5.1 is the constant daily movement of individuals and families between them, as well as beyond the region. For a census that is dwelling-focused, rather than population-focused, this makes counting people a difficult process.

The emphasis in the conduct of the census was to ensure that every dwelling in the region had at least one completed IHF, either with the details of people present or to the effect that the dwelling was unoccupied. This was precisely in line with instructions in the Community Coordinator Manual and the Working for the Census Guide for Interviewers. Accordingly, there was a clear sense in which the count would be considered accomplished at the point when all known dwellings had been processed. Leaving aside some checking of forms by the $\mathrm{CFO}$ and CCs to ensure that all questions had been completed, no mechanism was deployed in the field to establish the population coverage of the count in the sense advocated by Martin and Taylor (1996) - again, apparently in line with census instructions, although some confusion reigns here. According to an internal ABS discussion paper on the 2006 IES, before the census forms were to leave communities, CFOs were to check all forms against community lists where possible. This was to help verify counts and coverage, and if insufficient coverage or errors were identified these were to be corrected before returning the forms to the CMU - in this case, in Darwin. This did not occur at Wadeye. Instead, on Saturday 5 August - 13 days after arriving in the town - the CFO left for Darwin with all the forms that had been completed up to that point and quality checking was then done at the CMU (see Chapter 7). 
One thing that was clear, however, was that the checklist procedure at Wadeye did not work well. As a result, it was difficult in the final stages of the enumeration to know precisely which dwellings had been covered. The basic problem was that CIs often went to dwellings that were different to their allocation off the MDC. By the time the CFO left with all existing completed forms on 5 August, an unknown number of dwellings in town remained to be enumerated (although a figure of up to 20 was mentioned), while several outstations - including Nama, Wudapuli, Table Hill and Fossil Head-had still to be visited. Accordingly, some census forms were left behind with the CCs to continue with the enumeration while assessment of coverage was continued in Darwin by painstakingly matching the existing forms with known dwellings. Instructions for continued census follow-up were subsequently communicated to the CCs, and one of them continued to fill out census forms until the end of August. Final mopping up, however, did not occur until 9 September, when the CFO returned to Wadeye to collect the last of the forms.

On this issue of dwelling coverage, time and again the need for constant local intelligence from outside the census team on the whereabouts of families was underscored. Ideally, this should have been a primary role of the CCs, but their lack of detailed knowledge of the community prevented this. Almost immediately on day one, empty dwellings were encountered because people were away at funerals, had travelled to outstations or the dwelling was due for repair, and it was apparent that tracking occupants in line with the allocation of particular families to dwellings on the MDC was going to be a challenge. In order to gain a sense of the scale of this issue, a quick drive around Wadeye with a key informant on day two revealed that 15 dwellings were empty because their occupants were away from town.

The idea that all dwellings have a single family name associated with them - as per the IDC and the MDC - or the more conceptual notion that individuals necessarily 'belong' to particular dwellings was flawed given the prevalence of extended and multi-family or multi-dwelling social groupings involving considerable intra-community mobility. A degree of procedural confusion was also observed here with some interviewers holding the impression that if a person could not be allocated to a lot number they couldn't be counted. In a number of instances observed, however, it clearly helped that interviewers were sensitive to the prospect of joint family living arrangements and efforts were made to allocate individuals accordingly. Also, what might be thought of as a particular family dwelling did not always turn out to be so. A random comparison of the distribution of families by dwelling between the 2005 Thamarrurr community census results and the 2006 ABS Census indicated that a substantial redistribution within town and away from town had occurred in the intervening months. While some of this occurs anyway for various reasons, the destruction of many dwellings during community violence in 2006 produced considerable upheaval, 
with a chain reaction of redistribution occurring as families regrouped into safer social clusters and locations.

\section{Persons temporarily absent}

Sometimes, dwellings that CIs and CCs thought were deserted turned out to be otherwise, but only because someone at the TRC chanced to point this out. Likewise, late in the count, no one in the census team seemed aware that a whole (and large) family group had been overlooked because the dwelling they were usually associated with was in disrepair. It transpired-when the team was informed again by the council - that these people were camping in nearby bush and hurried arrangements were made to track them down. While not reflective of mobility, a similar oversight occurred towards the end of the enumeration with regard to aged pensioners at the respite centre who were also overlooked until a casual remark by the housing manager brought this to light.

The extended timing of the census compounds the complications caused by this residential mosaic. Because people travel into and out of Wadeye to outstations and elsewhere on a regular, sometimes daily, basis, the question of whether individuals were either overlooked or picked up twice - or even more times - as the enumeration rolled out, was very real. Of course, ABS checking procedures should have dealt with any of the latter cases, but no procedures were deployed to address the former. One classic example of this dilemma was played out around the public holiday weekend of the Royal Darwin Show, beginning on Friday 27 July. Because of anticipated lack of activity in town, the CFO decided to swing through some of the region's northern outstations during the holiday period and conduct the enumeration there. On the previous afternoon, after a large funeral for a young girl, numerous vehicles had turned up in Wadeye from outlying areas to stock up at the store for the long weekend. Among those moving in were many members of a large family group from one of the northern outstations that had a population in 2005 of about 80 people. By this time, the census at Wadeye had more or less wound down and was resumed again (slowly) only on the Monday. On that same day, the CFO was back in town to report that not many people were found at the outstations and that some dwellings were vacated for a funeral ceremony. Almost simultaneously, most of the same aforementioned family group members were beginning their circuitous route back home. This raised the prospect that these people were not counted, although it should be noted that the CFO's trip also uncovered people at outstations who had already been counted in town.

Likewise, a group of older people who had been at Tchindi Outstation - which wasn't visited by the census team on the assumption that no one was there - eventually turned up in town and were enumerated at a previously listed vacant dwelling, but only because one of the CCs was informed of their arrival by a council employee. Elsewhere, two dwellings at Wudapuli Outstation - which 
was not visited until the middle of August - were found empty because the occupants had moved temporarily to Warmun in the east Kimberley for ceremonial business. Interestingly, an attempt was made by the CMU in Darwin to extract information on this group from ABS colleagues in Western Australia, but to no avail. It is also likely that the lack of people at Kuduntiga Outstation as reported by one of the CCs was due to their absence at ceremonial business in Elliot. These types of oversight and failures to track people seem inevitable when following a dwelling-focused census methodology that is extended over time among a mobile population. While at one level the extended nature of the census count can assist by allowing time for people to move (literally) into scope, the main lesson from Wadeye is that this is likely to assist their enumeration only if constant input of local intelligence on the whereabouts of people forms part of the process.

Confusion of this sort was not aided by an at times somewhat culturally inflected interpretation of the wording to Questions 10 and 11 on the part of interviewers and respondents. Question 10 asks, 'Are there any persons who live here most of the time but are away?' Given that high levels of temporary mobility are known to exist among the regional population, it was curious to the observer that affirmative answers to this question were very few, yet in a number of households where individuals were known to the observer to be away in other locations - in the sense that the ABS meant - their absence was not recorded. On quizzing interviewers about this issue, the fact that they were 'away' - and in cases could have been so for some days - did not register as an absence. This was not because respondents made a judgment that they were likely to be counted elsewhere - as per the instruction for Question 11, the 'Persons Temporarily Absent' (PTA) table (see Appendix A) - rather it was because they were still considered to be part of the present household and therefore not away. In any case, the idea that respondents, or CIs, could assess whether absent people might be counted elsewhere was highly presumptuous and generally avoided, at least in those instances observed.

This 'not absent' response was all well and good if such people subsequently appeared in answer to Question 12. A sometimes literal interpretation of 'people who are living or staying here now' (my emphasis, meaning 'at this moment'), however, meant that in some cases (admittedly only three observed) people who were absent at the shops, or were out bush for the day, were omitted. In an interesting variation on this, an instance was observed of a new-born child who was omitted from a household count because it had just left with its mother for the day to Palumpa and no one knew its name. Some confusion also arose over whom to indicate as Person 1 in Question 12 if the head of the household was listed as a PTA in Question 11. One final aberration surrounded the category 'visitor'. Though few people seemed to nominate this, where it was used the 
individuals referred to were fairly long-term residents and the term 'visitor' was clearly being used as a social category as much as a residential one.

As mentioned, a common characteristic of the Wadeye Aboriginal population - and of Aboriginal populations across the Northern Territory for that matter - is their temporary movement into regional centres such as Darwin for a wide variety of reasons ranging from service access and recreation to funerals. This movement is heightened in the dry season, and was augmented in 2006 by civil disorder and by the fact that the official start of counting at Wadeye (26 July) coincided with public holiday weekends, first for the Royal Darwin Show (27-29 July). The Darwin Cup (5-7 August) presented an additional attraction at that time for Wadeye residents. According to local informants, other places where usual residents of the Thamarrurr region were to be found during August 2006-aside from those already mentioned-included Palumpa, Peppimenarti, Daly River, Belyuen, the Tiwi Islands, Milingimbi, Wyndham, Kununurra and the greater Darwin area.

When visiting Darwin, Wadeye people locate themselves in various residential settings including in conventional housing with relatives in town or in motels, at town camps such as Railway Dam, Knuckey's Lagoon and Palmerston, at the Bagot Community and at various camping spots near the Catholic Mission headquarters in Stuart Park, by the Murin air terminal, the Airport Hotel, Lim's Hotel, Nightcliff Oval, the Catholic Mission hostel at Berrimah and along Rapid Creek. Given the likely numbers involved-estimated anecdotally in August 2006 at about 200 people - a key issue for the usual residence count of the Wadeye population was whether these people were captured by the census in Darwin and, if so, how the various forms used were filled out.

For example, those in conventional housing or in motels should have been captured as visitors on the standard mainstream form in answer to Question 2, but to be part of the Wadeye usual residence count they would need to have indicated 'Wadeye' in answer to Question 8 on usual residence. Those in town camps faced a similar combination of questions and issues, in Questions 12 and 15, on the IHF. For those camping out in urban areas, the general strategy employed by the ABS in the Northern Territory was to use the standard Special Short Form designed for homeless people. According to the CMU, this was deployed for two days from 9 August at known regular camping sites around the Darwin urban area. The particular feature of this form and its application that has importance for census counts is that it contains no question on usual residence. Information was primarily obtained through interview or self enumeration as the first preference, or by observation when circumstances prevented this. For Wadeye residents who were camping out in Darwin-and in any other urban area in the Northern Territory - the ABS, however, adopted a different approach in recognition of the large-scale dispersal of Wadeye 
residents that occurred due to community tensions just before the census. The procedure for this group was to use abridged mainstream forms (household and personal) rather than the Special Short Form, therefore activating the usual place of residence question. While this was well intentioned, it turned out that only a small number of 'homeless' Wadeye people were enumerated successfully using this approach, so any individuals enumerated in other camping locations using the standard Special Short Form method would have been lost to the Wadeye usual resident count.

\section{Conclusion}

Observation of the 2006 IES in the large Aboriginal town of Wadeye and its hinterland uncovered a range of structural issues concerning ABS interactions with community representatives, the strategies adopted to engage, train and supervise an Indigenous census workforce, the logistics deployed to connect with a mobile and scattered population and the categorisations and interpretations associated with the census questions, which are likely to have impacted on the successful outcome of census goals. At one level, this is surprising, since many of the contingencies faced were entirely predictable. At another level, it is not, because it reflects a continuing lack of meaningful engagement between citizens to be counted and the nation-state.

Despite the cultural importance in the Aboriginal world of the area between the Daly and Fitzmaurice Rivers, from a non-Aboriginal perspective this was one of the least-known parts of the continent until the mid 1930s and numbers resident there were simply guesstimated for prewar censuses and then incorporated into the general estimate for the full-blood Aboriginal population for the entire Daly River Census District. All this began to change with the establishment of the Catholic mission in 1935, first at Wentek Nganayi, then at Port Keats (now Wadeye) in 1939. From the very outset, a key task of mission administration in the region was regular census-taking. This was a requirement in the postwar years as part of annual reporting, initially to the Native Affairs Branch, then, from 1953, to the Welfare Branch of the Northern Territory Administration (Taylor 2005). Subsequently, the official count of the population has been sourced via the five-yearly ABS census. From 1976 to 1996, this provided a count of individuals present at Wadeye on census night, with those at outstations simply included as part of a much larger number representing the balance of the entire Daly Statistical Local Area. For the 2001 Census, however, outstations located in the Thamarrurr region were identified collectively for the first time as an Indigenous location. As we have seen, in the Realpolitik of community funding and representation, the TRC has also of late engaged in enumerating its population. Since census-taking is clearly not new to the region, why then - from observation - does it seem so difficult to accomplish? 
One of the ABS responses to suggestions for improving the IES was to focus on form redesign. While the effect of changes made in this regard could be established at Wadeye only a priori, there was no doubt that the new census form proved to be a highly practical instrument to administer-leaving aside issues to do with the actual questions on the form and their interpretation. In all likelihood, it would not be wrong to suggest that the single-form approach was of greater assistance to interviewers and respondents than the multi-form approach in working through what was an increasingly crowded census schedule. This, as it turned out, was the least of the issues at stake (for further comments, see Appendix B).

The fact is, no matter how good the form structure, in small-scale communal settings such as those found typically in remote Australia, other more structural and systemic issues dominate. These relate to levels of community preparedness, participation and sense of ownership in what is a substantial and highly visible interaction with government. If these are not the primary focus and concern of the IES then the task of enumeration is reduced to a direct encounter between the ABS and individual householders - a much more difficult task than working in full partnership with their representative organisations. This is not least because the IES methodology insists on a dwelling-count approach to capturing a mobile population, which heightens the need for a sufficient, knowledgeable, authoritative and experienced local census workforce. The way to secure such expertise is to strengthen the existing relations between the ABS and communities and ensure the participation of representative organisations in statistical matters as a continuing priority throughout the entire inter-censual period.

The thwarted attempts to assemble an adequate census workforce at Wadeye provide a case in point. These attempts were not assisted by a growing feeling of detachment from the census process on the part of community representatives, by disruptive communal tensions leading up to the census, by competing local demands for skilled workers and by the fact that Wadeye was just one port of call on the CFO's vast administrative canvas. Before dismissing these as constraints that were unique to Wadeye, my point is that they were entirely to be expected and likely to be increasingly systemic in the absence of drastically improved resourcing for remote community services and governance. The consequence was an effective census team of just four people to cover the largest Aboriginal settlement cluster in the Northern Territory. This resulted in a much longer than planned for enumeration period, difficulty in establishing census coverage and a loss of capacity for data-quality checking in the field.

In the inter-cultural world of remote Aboriginal communities, the idea that a single CFO plus an Assistant can successfully negotiate, instigate and manage the census enumeration across a vast area in a compressed period without full local support is fanciful. Rather than suggesting a case for more CFOs, however, 
the more radical solution here is to build greater capacity for continuing ABS relations with community organisations so that by the time the census comes around every five years, both parties are better positioned to work together in the process. Part of the problem at Wadeye, it would seem, was that the census came to be viewed solely as an ABS activity - much more so than in the mainstream census, where the responsibility is on the individual householder to self-enumerate, and increasingly so given online census access. In the IES, errors can arise precisely because the householder has far less control over the process and is much more dependent on the logistical capabilities of ABS officers and procedures (this is not to deny that the IES, as conceived, is a device to enhance Indigenous participation in the census). To foster closer collaboration, or partnership, it might help to pursue notions of rights and responsibilities around census-taking in much the same way that Shared Responsibility Agreements (SRAs) work for other areas of government activity. For example, at Wadeye, ABS access to the TRC population database for guidance on DOB data and data-quality checking might have been more likely to have eventuated if ground rules and modus operandi regarding confidential data access were negotiated more fully in advance.

Ultimately, the census has two broad objectives. The first is to measure accurately the number and key characteristics of people in Australia on census night and the dwellings in which they live. The second is to provide timely, high-quality and relevant data for small geographic areas and small population groups, to complement the rich but broad-level data provided by ABS surveys (ABS 2006a). The IES, of necessity, contravenes the simultaneity condition of the first of these objectives, and by so doing compromises its capacity to deliver on the second. The dominant finding from observation of events at Wadeye is that this structural weakness of the IES could be greatly ameliorated if Indigenous people and their representative organisations were adequately positioned and resourced to engage more meaningfully in the census process and thereby assume more - not less - responsibility for 'self-enumeration' in line with the rest of the Australian community. 